\title{
THE RAMSEY NUMBER FOR THETA GRAPH VERSUS A CLIQUE OF ORDER THREE AND FOUR
}

\author{
M.S.A. Bataineh \\ Department of Mathematics \\ Yarmouk University \\ Irbid-Jordan \\ e-mail: bataineh71@hotmail.com \\ M.M.M. JARADAT \\ Department of Mathematics, Statistics and Physics \\ Qatar University \\ Doha-Qatar
}

e-mail: mmjst4@qu.edu.qa

AND

M.S. BATEEHA

Department of Mathematics

Yarmouk University

Irbid-Jordan

\begin{abstract}
For any two graphs $F_{1}$ and $F_{2}$, the graph Ramsey number $r\left(F_{1}, F_{2}\right)$ is the smallest positive integer $N$ with the property that every graph on at least $N$ vertices contains $F_{1}$ or its complement contains $F_{2}$ as a subgraph. In this paper, we consider the Ramsey numbers for theta-complete graphs. We determine $r\left(\theta_{n}, K_{m}\right)$ for $m=2,3,4$ and $n>m$. More specifically, we establish that $r\left(\theta_{n}, K_{m}\right)=(n-1)(m-1)+1$ for $m=3,4$ and $n>m$.
\end{abstract}

Keywords: Ramsey number, independent set, theta graph, complete graph.

2010 Mathematics Subject Classification: 05C55, 05C35. 
[1] V. Chvátal and F. Harary, Generalized Ramsey theory for graphs, III. Small offdiagonal numbers, Pacific J. Math. 41 (1972) 335-345.

doi:10.2140/pjm.1972.41.335

[2] R. Bolze and H. Harborth, The Ramsey number $r\left(K_{4}-x, K_{5}\right)$, The Theory and Applications of Graphs (Kalamazoo, MI, 1980) John Wiley \& Sons, New York (1981) 109-116.

[3] L. Boza, Nuevas Cotas Superiores de Algunos Numeros de Ramsey del Tipo $r\left(K_{m}, K_{n}-e\right)$, in: Proceedings of the VII Jornada de Matematica Discreta y Algoritmica, JMDA 2010, Castro Urdiales, Spain July (2010).

[4] R.J. Faudree, C.C. Rousseau and R.H. Schelp, All triangle-graph Ramsey numbers for connected graphs of order six, J. Graph Theory 4 (1980) 293-300. doi:10.1002/jgt.3190040307

[5] M.M.M. Jaradat, M.S. Bataineh and S. Radaideh, Ramsey numbers for theta graphs, Internat. J. Combin. 2011 (2011) Article ID 649687. doi:10.1155/2011/649687

[6] J. McNamara, Sunny Brockport, unpublished

[7] J. McNamara and S.P. Radziszowski, The Ramsey Numbers $R\left(K_{4}-e, K_{6}-e\right)$ and $R\left(K_{4}-e, K_{7}-e\right)$, Congr. Numer. 81 (1991) 89-96.

[8] S.P. Radziszowski, Small Ramsey numbers, Electron. J. Combin. (2011) DS1.

Received 7 December 2011

Revised 13 February 2013

Accepted 13 February 2013 